\title{
Electrospun vancomycin-loaded coating on titanium implants for the prevention of implant-associated infections
}

\author{
This article was published in the following Dove Press journal: \\ International Journal of Nanomedicine \\ 23 June 2014 \\ Number of times this article has been viewed
}

\section{Li Zhang* \\ Junwei Yan* \\ Zhaowei Yin \\ Cheng Tang \\ Yang Guo \\ Dong $\mathrm{Li}$ \\ Bo Wei \\ Yan Xu \\ Qiangrong Gu \\ Liming Wang}

Orthopedic Laboratory of Nanjing First Hospital, Nanjing Medical

University, Nanjing, People's Republic of China

*Both of these authors contributed equally to this work
Correspondence: Liming Wang Orthopedic Department, Nanjing First Hospital, Nanjing Medical University, 68 Changle Road, Nanjing 210006, People's Republic of China Email limingwang99@163.com

\begin{abstract}
The objectives of this work were to develop an antibiotic coating on the surface of a titanium plate to determine its antibacterial properties in vitro and in vivo. To prepare vancomycincoated titanium implants, we adopted the electrospinning nanotechnique. The surface structure of the coating implants was observed using a scanning electron microscope. An elution method and a high-pressure liquid chromatography assay were used to characterize the release behavior of vancomycin from the coating. The antibacterial efficacy and the cytotoxicity of the coated titanium implants on osteoblasts were investigated in vitro. In addition, X-ray, white blood cell count, C-reactive protein, erythrocyte sedimentation rate, and pathological examination were performed to validate its antimicrobial efficacy in vivo. The antibiotic coating released $82.7 \%$ (approximately $528.2 \mu \mathrm{g}$ ) of total vancomycin loading in the coating in vitro. The release behavior of vancomycin from nanofiber coatings exhibited a biphasic release pattern with an initial burst on day 1 , followed by a slow and controlled release over 28 days. There was no cytotoxicity observed in vitro for the vancomycin-loaded coating. The vancomycin-coated titanium implants were active in treating implant-associated infection in vivo. Thus, vancomycin-coated titanium implants may be a promising approach to prevent and treat implant-associated infections.
\end{abstract}

Keywords: electrospinning, vancomycin, implant, infection, coating, nanofibers

\section{Introduction}

With the development of orthopedic surgery techniques and the improvement of orthopedic implants, the number of patients with a need for orthopedic implants has increased rapidly over the past few years. ${ }^{1}$ Patients show a higher susceptibility to infection due to bacterial contamination and soft-tissue damage, particularly in invasive orthopedic surgery. ${ }^{2}$ As a result, an accompanying increased risk of infection related to implants has been observed. ${ }^{3}$ Implant-associated infections following invasive orthopedic surgery are a major clinical problem and are one of the main causes of implant failure.

Current strategies for the management of implant-associated infections are the administration of perioperative systemic antibiotics. Although antibiotics can be administered systemically as part of routine clinical therapy, a high concentration of the drug may not be achieved at the desired site with systemic administration. ${ }^{1}$ Systemic antibiotic administration may result in various systemic toxicities and the development of antibiotic-resistant micro-organisms. ${ }^{4}$ For this reason, a localized, controlledrelease antibiotic delivery strategy, where the antibiotic is targeted to the desired site and released at high concentrations over a prolonged period of time, is thought to be a promising alternative approach to systemic antibiotic administration..$^{5-7}$

Staphylococcus aureus is thought to be the common cause of implant-associated infections. ${ }^{8}$ Vancomycin belongs to the antibiotic family of glycopeptides. It was 
chosen as the loading antibiotic for the following reasons. First of all, it has a broad antimicrobial spectrum that covers most bacteria, such as methicillin-resistant $S$. aureus and methicillin-resistant $S$. epidermidis. A toxic dose of vancomycin $(1,000 \mu \mathrm{g} / \mathrm{mL})$ is relatively low compared with other commonly administrated antibiotics such as gentamicin, rifampicin, and tobramycin., 9

Owing to the advent of nanotechnology, there has been an interest in utilizing this emerging science for a number of orthopedic applications. ${ }^{11}$ Electrospinning, a promising processing technique that utilizes electrical forces to produce ultrafine polymeric fibers using polymer solutions, has been developed in recent years. ${ }^{12}$

The resulting electrospun fibers have been successfully explored as tissue-engineering scaffolds for vasculature, ${ }^{13}$ bone, ${ }^{14}$ neural, ${ }^{15}$ and tendon tissues ${ }^{16}$ and delivery systems for a wide range of drugs, including antibiotics, ${ }^{17,18}$ because of their high porosity, highly specific surface area, good cell adhesion, and controlled drug release. ${ }^{19}$

The objective of this work was to develop an antibiotic coating on the surface of a titanium plate to determine its anti-infective properties in vitro and in vivo. The following experiments were also performed: 1) the amount of the vancomycin contained in the coating; 2) the surface morphology of the coated implants; 3 ) the in vitro release behavior of vancomycin from the coating; 4) the cytotoxicity of the coating in vitro; 5) X-ray, white blood cell count (WBC), C-reactive protein (CRP), erythrocyte sedimentation rate (ESR), and histological examination were performed to validate vancomycin-coated titanium implants' antimicrobial efficacy in the in vivo study.

\section{Materials and methods}

\section{Preparation of the vancomycin-loaded coating}

The titanium implants used in this study were purchased from Health Medical Treatment Apparatus Co., Ltd (Suzhou, People's Republic of China). Poly(lactic-co-glycolic acid) (PLGA) with a lactide:glycolide ratio of 50:50 was purchased from Daigang Biotechnology Co., Ltd (Shanghai, People's Republic of China). Trifluoroethanol was purchased from Darui Finechemical Co., Ltd (Shanghai, People's Republic of China). The vancomycin was purchased from Eli Lilly Japan K.K, Seishin Laboratories (Kobe, Japan).

The electrospinning apparatus utilized in this study consisted of a high voltage source, a needle, a syringe pump, and an aluminum-collecting screen, supplied by the State Key Laboratory of Bioelectronics, Southeast University, Nanjing, People's Republic of China. Briefly, PLGA (50:50; molecular weight $(\mathrm{MW})=80,000 \mathrm{Da})$ was codissolved with vancomycin $(10 \%$ weight/weight $[\mathrm{w} / \mathrm{w}])$ in trifluoroethanol to achieve a final concentration for total solids of $0.4 \mathrm{~g} / \mathrm{mL}$. The solution was then delivered and electrospun using a syringe pump with a volumetric flow rate of $2.5 \mathrm{~mL} /$ hour. The titanium implants were fixed on the aluminum foil as a collector. The positive voltage applied to the polymer solutions was $12 \mathrm{kV}$, and the distance between the spinneret and the collector was $15 \mathrm{~cm}$. All of the electrospinning experiments were carried out at room temperature with humidity at $40 \%$. After the coating procedure, all these specimens were dried under vacuum at room temperature for 2 days to completely remove solvent residue. Both the vancomycincoated and the polymer-coated titanium implants were prepared according to these methods. Subsequently, all of these titanium implants were sterilized by $25 \mathrm{~K}$-Gray gamma radiation for the following experiment.

\section{Scanning electron microscope observation and drug loading}

The morphology of the vancomycin-loaded coating was observed using a Hitachi S4800 scanning electron microscope (SEM) (Hitachi, Tokyo, Japan) after gold coating. The diameter distribution and average diameter of the two coating groups were obtained by analyzing SEM images using Image J software (National Institute of Mental Health, Bethesda, MD, USA). We randomly selected vancomycin-coated titanium implants $(n=12)$ and weighed each plate before and after the coating procedure. Next, the mean weight of the coating was determined using SAS (version 9.1.3; SAS Institute, Cary, NC, USA) after excluding the maximum and the minimum values. The amount of vancomycin in the coating was accurately calculated according to the formation of polymer solutions.

\section{In vitro release behavior of vancomycin}

An elution method and a high-pressure liquid chromatography (HPLC) assay (Shimadzu Corporation, Kyoto, Japan) were used to characterize the release behavior of the vancomycin from the coating. The implants were immersed in $10 \mathrm{~mL}$ of phosphate buffer at $\mathrm{pH} 7.4$ and incubated in a thermostatically controlled oven at $37^{\circ} \mathrm{C}$ under gentle rotation. At predetermined time intervals $(1,7,14$, and 28 days), specimens of $1 \mathrm{~mL}$ samples were withdrawn for HPLC, and the remaining medium was removed and replaced with fresh phosphate-buffered saline at $\mathrm{pH}$ 7.4. The studies were carried out in triplicate.

\section{In vitro cytotoxicity assay}

In this study we utilized the Cell Counting Kit-8 (Dojindo, Kumamoto, Japan) to measure cell viability. First, both 
the vancomycin-loaded coating and polymer coating samples on circular glass slides with a diameter of $1 \mathrm{~cm}$ were prepared by the electrospinning process. All of these specimens were sterilized ( $25 \mathrm{~K}$-Gray gamma radiation) for the following studies. Osteoblastic MC3T3-E1 cells were cultured in Dulbecco's Modified Eagle's medium supplemented with $10 \%$ fetal bovine serum and $10 \mathrm{U} / \mathrm{L}$ penicillin and streptomycin in a $5 \% \mathrm{CO}_{2}$ incubator at $37^{\circ} \mathrm{C}$. MC3T3-E1 osteoblasts cells in the complete growth culture medium were seeded at a density of $5 \times 10^{3}$ cells/well on bare circular glass slides, vancomycin-coated circular glass slides, and polymer-coated circular glass slides in 48-well plates. After cell seeding, the culture medium was removed on days 1,3 , and 5 . Then, $20 \mu \mathrm{L}$ of Cell Counting Kit-8 (CCK-8) solution (Dojindo Laboratories, Kumamoto, Japan) mixed with $200 \mu \mathrm{L}$ of fresh cell culture medium was added to each well and incubated for 3 hours, before $100 \mu \mathrm{L}$ of solution was transferred to a 96-well plate. Finally, we estimated the fluorescence at $450 \mathrm{~nm}$ by a microplate reader (Bio-Rad Laboratories Inc., Hercules, CA, USA) to measure cell viability.

\section{The antibacterial efficacy of the vancomycin-loaded coating in vitro}

Because Staphylococci are the most common micro-organisms that cause implant-related infections, we chose $S$. aureus as the experimental bacterial strain. ${ }^{20}$ This study was divided into three groups: the vancomycin group, the polymer group, and the bare group. The $S$. aureus strain (American Type Culture Collection [ATCC] 29213) used in this study with a density of $1.5 \times 10^{8}$ colony forming units (CFU)/mL was supplied by the Department of Laboratory Medicine, Nanjing First hospital, Nanjing Medical University. A total of $0.5 \mathrm{~mL}$ of this bacterial suspension was inoculated uniformly on each Mueller-Hinton plate (Keygene Biotechnology Co. Ltd., Nanjing, China). Next, a sterilized, $6 \mathrm{~mm}$ diameter circle of paper was placed individually on each Mueller-Hinton plate. A total of $20 \mu \mathrm{L}$ derived from the aforementioned elution study was dropped on to the paper circle. The time intervals $(1,7,14$, and 28 days) of solution extraction were consistent with an in vitro vancomycin release study. After that, the plates were incubated at $37^{\circ} \mathrm{C}$ for 24 hours, after which the zones of inhibition around each paper circle were measured.

\section{The antibacterial efficacy of the vancomycin-loaded coating in vivo}

Thirty-six New Zealand male rabbits weighing 2.5-3.0 kg were randomly divided into three groups in this in vivo study: the vancomycin group $(n=12)$, the polymer group $(n=12)$, and the bare group $(n=12)$. All animal procedures were carried out in conformity with the guidelines on the protection of animals used in experiments. The New Zealand rabbits were obtained from the Laboratory Animal Center, Nanjing Medical University. For the in vivo study, the density of S. aureus was diluted to $10^{6} \mathrm{CFU} / \mathrm{mL}$. To test the ability of the vancomycin-loaded coating to prevent the implantassociated infection in vivo, we produced a rabbit model of tibia transverse and infected fracture as per Arens et al. ${ }^{21}$ All animal surgical procedures were operated under sterile conditions. After induction of anesthesia, the skin over the medial aspect of the midshaft of the tibia was incised. Retraction of the muscles allowed tibia exposure, and manufactured transverse fracture of the tibia used a wire saw. The titanium implants were then fixed to the medial aspect of the tibia. A total of $100 \mu \mathrm{L}$ of the $S$. aureus suspension ( $\left.10^{5} \mathrm{CFU}\right)$ was introduced into the transverse fracture site before closing the incision. WBC, CRP, and ESR experiments were performed the day before surgery and on the first and fourth week after surgery. On postoperative day 28, all the animals were sacrificed using an overdose of isoflurane. X-ray examinations were obtained on the 28th day after surgery. Both bone and soft tissue surrounding each titanium implant were excised and preserved in sterile $10 \%$ buffered formalin for histopathological analyses. The study and its design were approved by the local animal ethics committee (Nanjing First Hospital Affiliated to Nanjing Medical University).

\section{Statistical analysis}

Data are expressed as mean \pm standard deviation, and the database was analyzed using SAS software (version 9.1.3). Significant differences were analyzed using the Student's $t$-test. The results of cell viability data were analyzed using repeated-measures analysis of variance, and the StudentNewman-Keuls test was used for comparisons among groups. All statistical tests were two-sided and $P<0.05$ was considered to be statistically significant.

\section{Results and discussion}

Despite noteworthy advances in antimicrobial therapy and orthopedic surgical techniques, implant-related infection can be ravaging and is associated with poor functional outcomes and high treatment expenditure. Approximately 2.6 million orthopedic implants are performed annually in the United States. ${ }^{22}$ As the number of orthopedic surgeries increases, the incidence of implant-associated infection is also increasing. ${ }^{23}$ Meanwhile, patients show a higher susceptibility to infection 
due to bacterial contamination and soft-tissue damage, particularly in invasive orthopedic surgery. ${ }^{2}$ Thus, implantrelated infection is still a difficulty for us.

In order to solve this problem, various local antibiotic delivery studies have been conducted to reduce the frequency of implant-related infection. Local antibiotics have the advantage of delivering high drug concentrations to the required site, and the total drug dose applied locally is not normally sufficient to produce systemic toxicity. Some scholars have put forward some points of view on antibiotic-coated implants or metal ions as local drug delivery systems to treat infection. Gollwitzer et al ${ }^{24}$ prepared a biodegradable drug delivery coating that was loaded with teicoplanin or gentamicin on the surface of implants, followed by studying adhesion of viable bacteria and antibiotic release. Schmidmaier et a ${ }^{25}$ reported that intramedullary tibial nails coated with gentamicin were Communauté Européenne-certified for Europe and Canada. Eight patients with open tibia fractures have been treated with gentamicin-coated intramedullary tibial nails. None of the patients developed infection during the follow-up. Hardes et al ${ }^{26}$ utilized silver-coated prostheses to treat patients with bone sarcoma and found that the use of silver-coated prostheses can reduce infection rate in the medium term. Fiedler et $\mathrm{a}^{27}$ prepared silver ion-coated titanium alloy and studied its antibacterial effects and proliferative response of osteoblasts in vitro. They reported that silver ion coating can inhibit colony incidence of S. aureus without cytotoxicity.

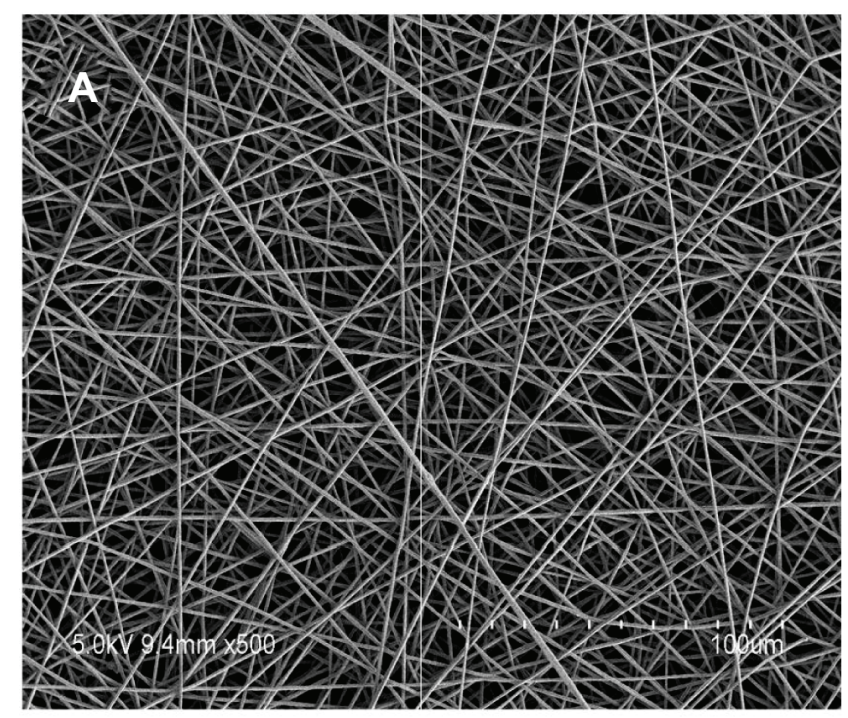

\section{The morphology of the coating and the amount of vancomycin}

Continuous, defect-free fibers were produced by vancomycin-loaded formulation, with narrow size distributions. A prepared sample is shown in Figure 1. The polymer group (without vancomycin) showed a similar morphology to the coated nanofiber coatings with smooth surface and round cross-sections. However, vancomycin-loaded nanofiber caused a significant decrease in its diameter from $983 \pm 86 \mathrm{~nm}$ (polymer group) to $728 \pm 72 \mathrm{~nm}$. The mean weight of vancomycin was $627.6 \pm 46.2 \mu \mathrm{g}$ for each vancomycin-coated titanium implant.

In our study, the biodegradable PLGA coatings were produced by an electrospinning technique. Electrospinning is a novel nanotechnology for biomedical application. ${ }^{28}$ Electrospinning can produce continuous, defect-free fibers in a range with narrow size distributions. We found the nanofiber diameters were significantly decreased by the presence of drug (vancomycin) compared with the polymer group (without vancomycin). A lower concentration of PLGA in the solution is thought to be the cause of this decrease in diameter. Some researchers reported that these nanofibers can promote cell adhesion and growth owing to their porosity and highly specific surface area..$^{29,30}$

\section{In vitro release of vancomycin from titanium implants}

Data on the in vitro release behavior of vancomycin from titanium implants are represented in Figure 2. The release

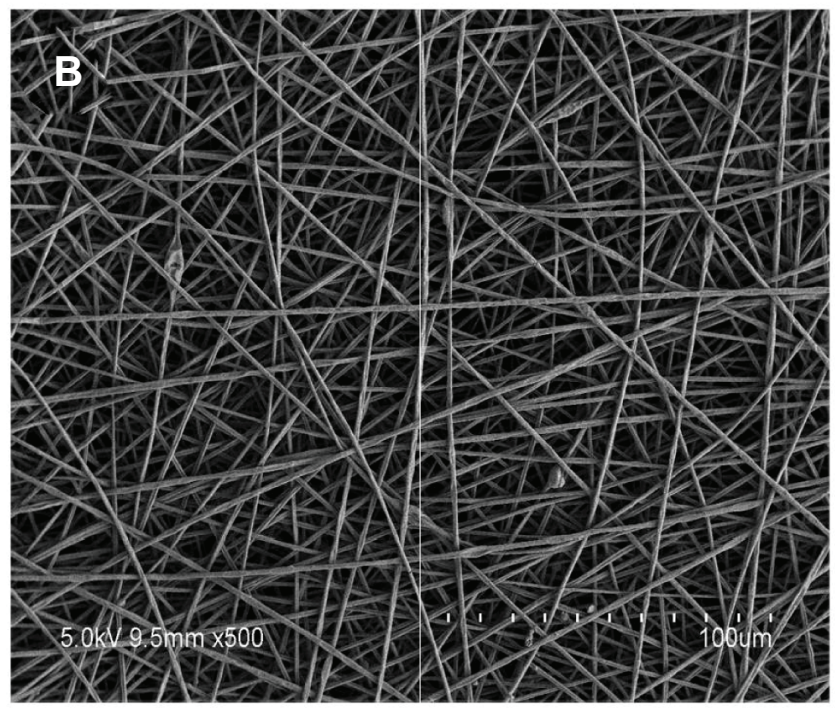

Figure I Representative scanning electron micrographs of electrospun coatings containing (A) 10\% (weight/weight) vancomycin and (B) no drug. Both of the formulations produced continuous, defect-free nanofibers with no visible evidence of phase separation. The scale bar in each micrograph represents $100 \mu \mathrm{m}$. 


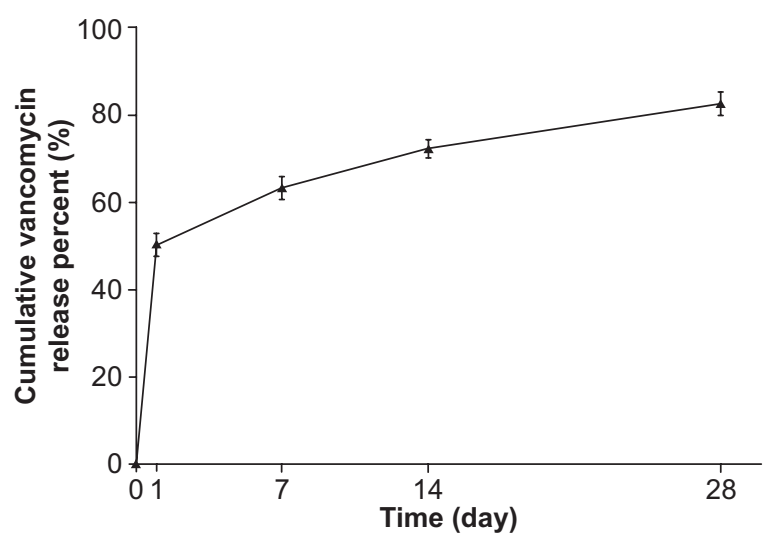

Figure 2 In vitro release profiles of vancomycin from the vancomycin-coated titanium implants performed in phosphate-buffered saline at $37^{\circ} \mathrm{C}$ exhibited an initial burst release, followed by a slow and controlled release.

behavior of vancomycin from nanofiber membranes exhibited a biphasic release pattern with an initial burst on day 1 , followed by a slow and continuous release over 28 days. Approximately $50.3 \%$ of the vancomycin was released in the initial burst on day 1 (vancomycin at a concentration of $31.8 \mu \mathrm{g} / \mathrm{mL}$ ). After the initial burst, a slow and controlled release (the 4-week test period) accounted for $82.7 \%$ (approximately $528.2 \mu \mathrm{g}$ ) of total vancomycin loading in the coating.

\section{CCK-8 cytotoxicity evaluation}

We used a CCK-8 assay to measure cell viability after cell culture for 1, 3, and 5 days. As shown in Figure 3, on the first day of cell seeding there was no significant difference between the bare circular glass slides and the other coated circular glass slides $(P>0.05)$. On day 3 and day 5, cells of the vancomycin-coated circular glass slides and the polymer-coated circular glass slides showed better growth

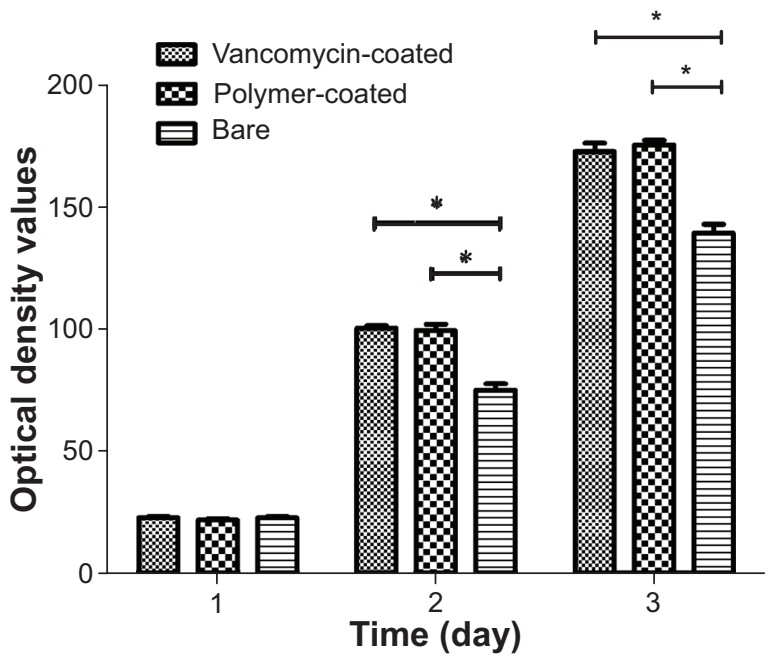

Figure 3 Cell viability measured by Cell Counting Kit-8. Asterisk represents the significant difference between the two groups $(P<0.05)$.

Note: Cell Counting Kit-8; Dojindo Laboratories, Kumamoto, Japan. than those on the bare circular glass. However, no significant difference between the vancomycin-coated circular glass slides and the polymer-coated circular glass slides was observed $(P>0.05)$. The cell-promoting effect of the nanofibers was validated in our in vitro cytotoxicity assay, which indicated that the vancomycin and polymer groups promoted cell growth more dramatically than the bare group. Therefore, the results of the cytotoxicity assay show that the coatings are not toxic to the cells.

\section{In vitro antimicrobial efficacy of the vancomycin-loaded coating}

The results of the inhibition zone test validated the antimicrobial efficacy of the vancomycin-loaded coating. When the samples from the polymer group or the bare group loaded, there were no obvious changes indicating that the polymer coating or the bare titanium implant did not affect bacterial growth. In contrast, a clear inhibition zone was formed for all of the bacterial dish in the vancomycin group. Moreover, the inhibition zone of the vancomycin group was maximum on the first day (average diameters of $12.7 \pm 0.4 \mathrm{~mm}$ ), as shown in Figure 4A. During the next testing period, the diameters of the zone of inhibition remained around $8 \mathrm{~mm}$ (Figure 4B-D). The results of the inhibition zone test were basically consistent with the vancomycin release behavior, further suggesting a biphasic release pattern with an initial burst and a controlled release of the vancomycin coating.

After the preparation of the antibiotic coating and the gamma radiation sterilization, we were unsure whether the vancomycin would maintain its biological activity. Consistent with our expectation, it does not lose its effectiveness from our in vitro and in vivo test results. The vancomycin-loaded coating did inhibit the growth of $S$. aureus bacteria in vitro. The antibacterial effect of vancomycin coating was validated by the inhibition zone. The control groups showed that no inhibition zones were observed. From the results of the inhibition zone test and elution study, we confirmed that vancomycin coating has a burst release and the strongest antibacterial properties on the first day, followed by a slow and controlled release over 28 days. These results were strongly supported by results obtained from some other researchers. Gilchrist et $\mathrm{al}^{31}$ used the electrospinning technique to prepare fusidic acid and rifampicin-coloaded PLGA nanofibers to prevent orthopedic implant-associated infections. The similar biphasic release behavior was shown in their in vitro drug release study. Some authors hold that the initial burst is due to the high solubilization of the drug located on the surface of the nanofibers, and the maintenance of the fibrous $m$ structure could 

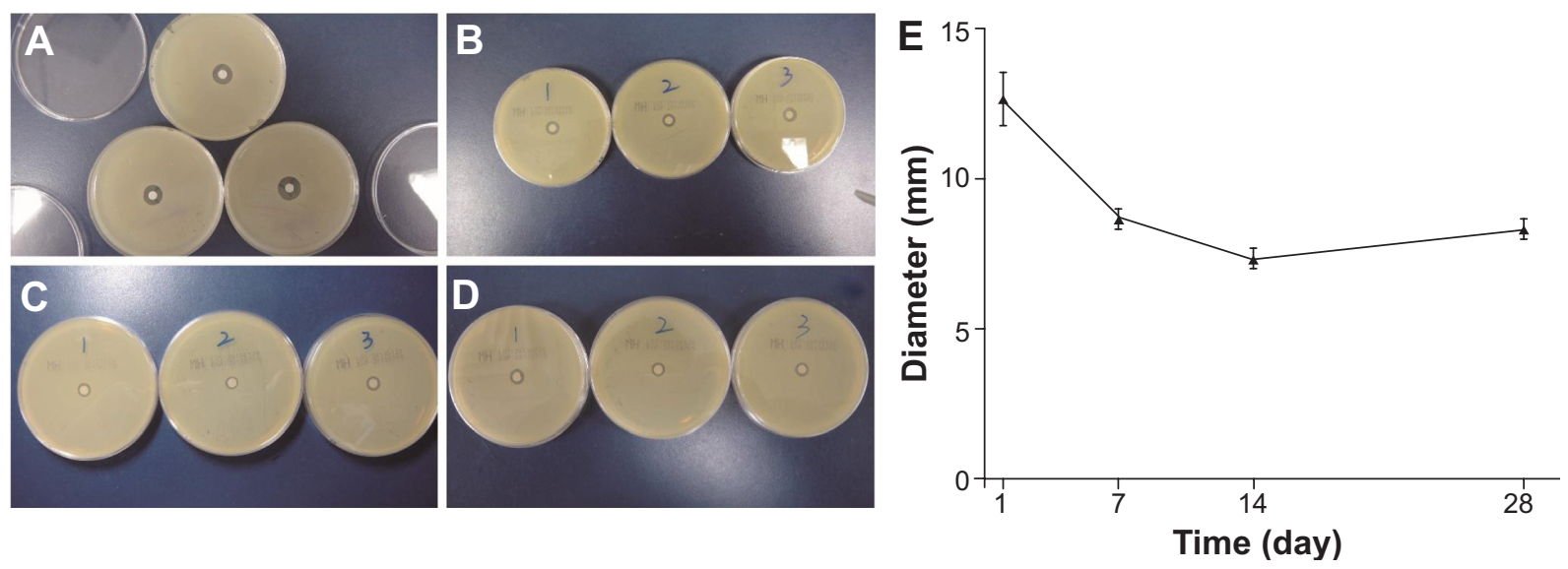

Figure 4 Representative photographs of the inhibition zone of the vancomycin group showing (A) day I, (B) day 7, (C) day I4, and (D) day 28. (E) The inhibition zone was at the maximum on the first day (average diameters of $12.7 \pm 0.4 \mathrm{~mm}$ ). During the next testing period, the diameters of the zone of inhibition remained around $8 \mathrm{~mm}$.

contribute to the controlled drug release at a fairly constant rate until the end of the study. ${ }^{32}$ Thus, the vancomycin-loaded coating does exert such functions in our studies.

\section{In vivo antimicrobial efficacy of the vancomycin-loaded coating}

Five animals (two animals from the polymer group and three animals from the bare group) died within a week after surgery. Sepsis was considered to be the cause of their death. Mortality did not appear in the vancomycin group.

WBC, CRP, and ESR were detected, respectively, on the day before surgery and the first and fourth week after surgery. The results are shown in Table 1. The results of this study showed that WBC and ESR of the rabbits in the bare and polymer groups after 1 week were significantly higher than those in the vancomycin group. Changes in the groups were found by analyzing serum markers at different time points. WBC and ESR of the rabbits in the bare and polymer groups showed an upward trend on postoperative day 28 , whereas WBC of the vancomycin group basically returned to the preoperative level. Although ESR of the vancomycin group had not yet returned to baseline on the 28th day, its index stabilized after the first week postimplantation. There was no significant difference in the CRP test among the three groups. This may be related to the latex agglutination assay, which was not sensitive enough for low concentrations of CRP.

Four weeks after the implantation, all the animals were sacrificed using an overdose of isoflurane. Figure 5 shows the macroscopic observation of the surgical site surrounding the implants on postoperative day 28. Pus and necrotic tissue were observed in the polymer and bare groups, but the obvious signs of infection had not occurred in the animals of the vancomycin group.

New bone formation and slight soft-tissue swelling were observed in the X-rays of the vancomycin group (Figure 6C). $\mathrm{X}$-rays of the polymer and bare groups revealed radiographic signs of osteolysis and serious soft-tissue swelling in all animals (Figure 6D).

All histological slices of the polymer and bare groups showed typical signs of infection: diffusive infiltration of inflammatory cells, degenerated muscle, and formation of necrotic tissue. In contrast, few abscesses, normal muscle tissue, and new bone tissue were observed in the vancomycin group (Figure 7).

Table I The results of serum biochemical parameters from three groups

\begin{tabular}{|c|c|c|c|c|c|c|c|c|c|}
\hline \multirow[t]{2}{*}{ Groups } & \multicolumn{3}{|c|}{$\begin{array}{l}\text { White blood cell count } 10^{9} / \mathrm{L} \text {, } \\
\text { (mean value, } x \pm s \text { ) }\end{array}$} & \multicolumn{3}{|c|}{$\begin{array}{l}\text { Erythrocyte sedimentation rate } \\
(\mathrm{mm} / \mathrm{hour}, \mathrm{x} \pm \mathrm{s})\end{array}$} & \multicolumn{3}{|c|}{ C-reactive protein $(\mathrm{mg} / \mathrm{L}, \mathrm{x} \pm \mathrm{s})$} \\
\hline & Preoperation & I week & 4 weeks & Preoperation & I week & 4 weeks & Preoperation & I week & 4 weeks \\
\hline Bare & $6.753 \pm 1.882$ & $10.534 \pm 1.073$ & $12.226 \pm 1.167^{\#}$ & $3.167 \pm 1.169$ & $17.175 \pm 1.812$ & $28.012 \pm 2.17 I^{\#}$ & $1.680 \pm 0.197$ & $1.625 \pm 0.283$ & $1.736 \pm 0.258$ \\
\hline Vancomycin & $6.350 \pm 1.544$ & $11.613 \pm 1.929$ & $7.218 \pm 1.322 *$ & $3.123 \pm 0.753$ & $15.722 \pm 2.353$ & $17.125 \pm 1.849 *$ & $1.802 \pm 0.232$ & $1.810 \pm 0.301$ & $1.773 \pm 0.294$ \\
\hline Polymer & $6.523 \pm 2.132$ & $\mid \mathrm{I} .732 \pm 1.408$ & $13.130 \pm 2.037^{\#}$ & $3.329 \pm 0.213$ & $18.327 \pm 2.645$ & $25.775 \pm 3.288^{\#}$ & $1.693 \pm 0.24 \mid$ & $1.693 \pm 0.142$ & $1.859 \pm 0.207$ \\
\hline$F$ & & 3.44 & 22.81 & & 31.6 & 198.86 & & 1.79 & 0.72 \\
\hline$P$ & & $0.074 I$ & $<0.000$ I & & $<0.000$ I & $<0.0001$ & & 0.1922 & 0.4950 \\
\hline
\end{tabular}

Notes: Compared with the control group, ${ }^{*} P<0.05$; compared with the vancomycin group, ${ }^{\# P}<0.05$. 

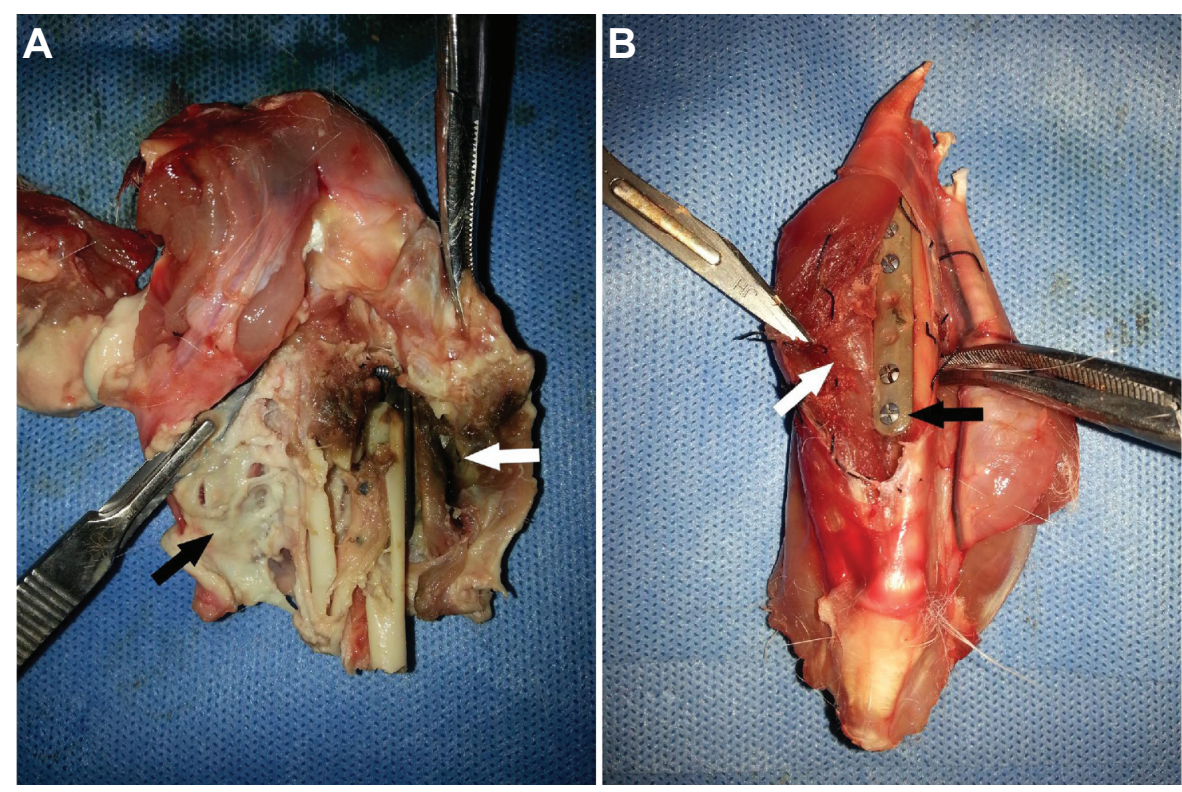

Figure 5 Macroscopic findings of the surgical site at week 4 after implantation. (A) Pus (black arrow) and necrotic tissue (white arrow) were observed in the groups without drug. (B) Basic normal bone and soft tissue (white arrow) were observed around the titanium implant, which was coated with incomplete degraded white vancomycin-loaded coating (black arrow).
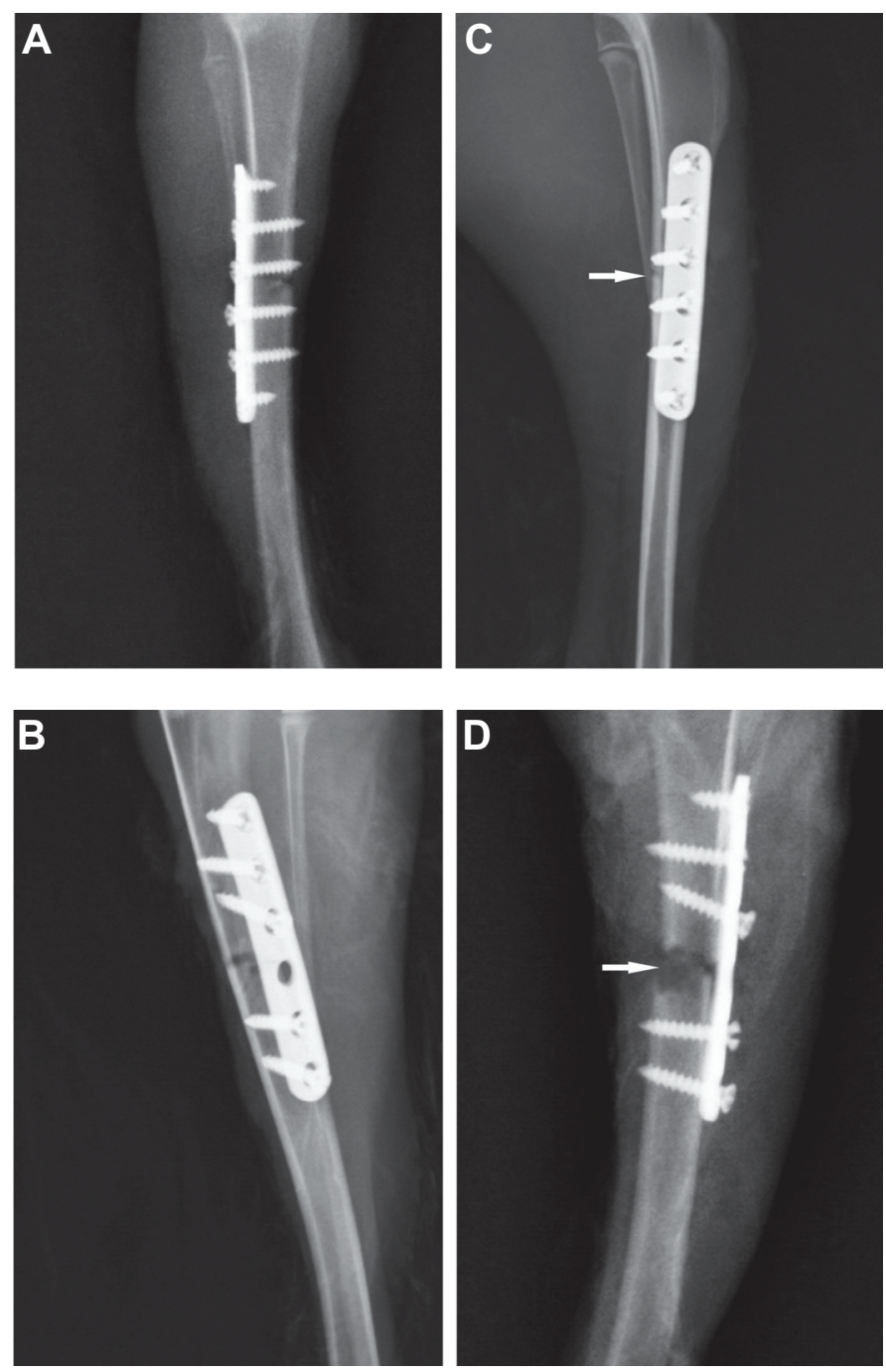

Figure 6 (A,B) Representative X-ray images after surgery. (C) Tibia with vancomycin-coated implant: new bone formation and slight soft-tissue swelling were observed. (D) Tibia without vancomycin-coated implant: osteolysis (white arrow) and serious soft-tissue swelling are clearly visible. 

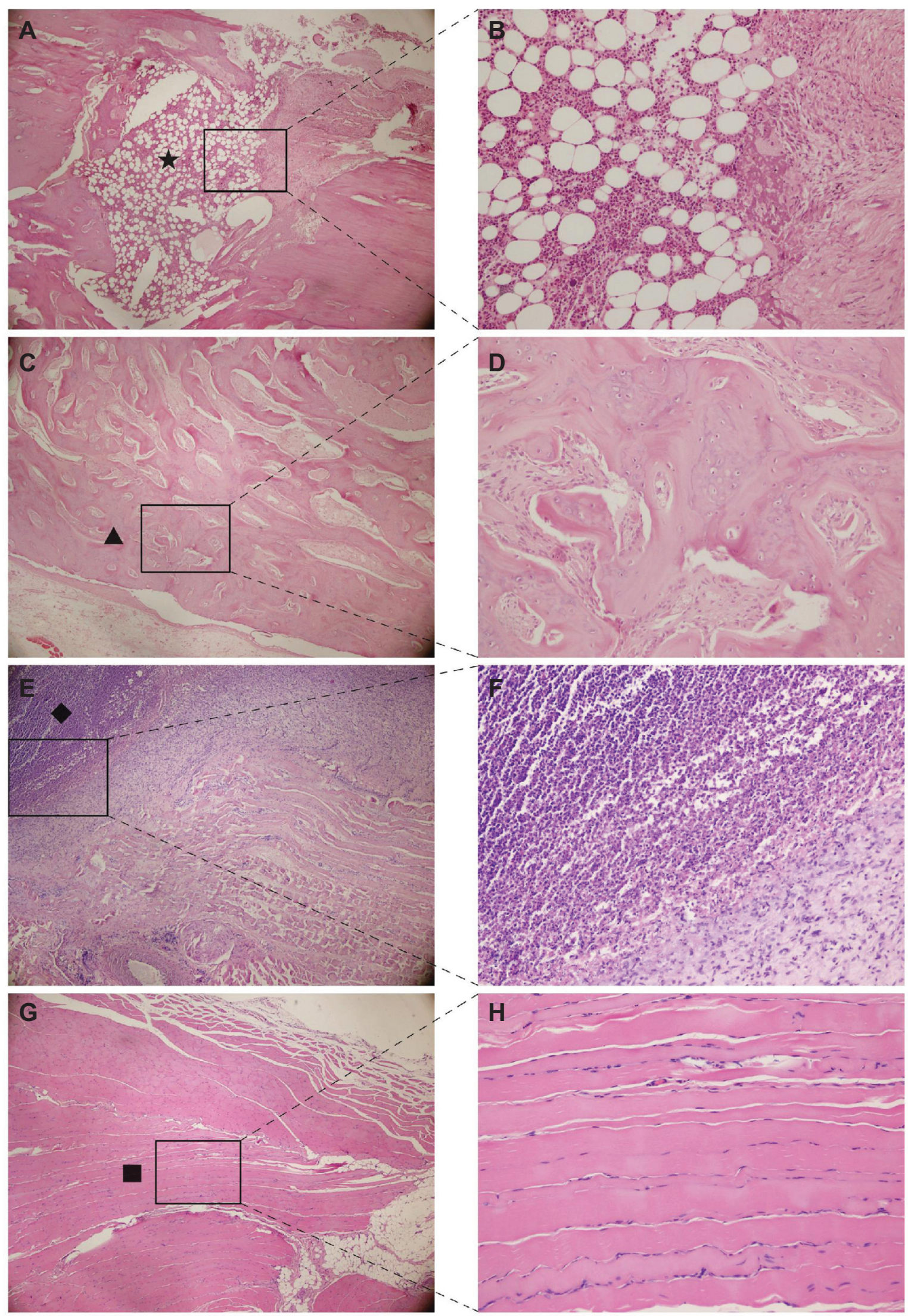

Figure 7 Hematoxylin and eosin staining of bone $(\mathbf{A}, \mathbf{C})$ and soft tissue around the implants (E,G). Magnified images in the squared area are displayed (B,D,F,H). Many inflammatory cells $(\mathbf{A}, \mathbf{B})$ were observed in the bone marrow cavity in the control group. Many abscesses $(\mathbf{E}, \mathbf{F})$ were located in the area around the control implant. New bone formation around the coating $(\mathbf{C}, \mathbf{D})$ and basic normal muscle $(\mathbf{G}, \mathbf{H})$ were observed in the vancomycin group. $(\mathbf{A}, \mathbf{C}, \mathbf{E}, \mathbf{G})($ magnification $\times 40) ;(\mathbf{B}, \mathbf{D}, \mathbf{F}, \mathbf{H})($ magnification $\times 200)$.

Notes: Black star represents inflammatory cells $(\mathbf{A})$. Black triangle represents new bone formation $(\mathbf{C})$. Black diamond represents abscesses $(\mathbf{E})$. Black square represents basic normal muscle (G). 
To the best of our knowledge, this is the first study to report antibiotic-loaded electrospun coating to prevent infection in an animal fracture model. In our previous investigation, we studied the antibacterial effects of gentamicin-loaded electrospun coatings on titanium implants in vitro. ${ }^{33}$ For further investigating the role of this antibiotic-loaded electrospun coating in the prevention of implant-associated infections in vivo, we carried out the animal experiments. Gilchrist et $\mathrm{al}^{31}$ prepared fusidic acid and rifampicin-coloaded electrospun coating to prevent the adherence of methicillin-resistant $S$. aureus to a titanium implant in an in vivo rodent model of subcutaneous implant-associated infection. Compared with their in vivo research, we had a better model of the clinical orthopedic trauma surgery. Tseng et a ${ }^{34}$ developed vancomycin-loaded, biodegradable PLGA nanofibrous membranes for the sustainable delivery of vancomycin to the brain tissue of rats by using the electrospinning technique. The results from our in vivo animal experiments suggest that vancomycinloaded coating can be advantageous in preventing implantassociated infections. Five rabbits from the control groups (without vancomycin) died of sepsis after surgery. The levels of WBC and ESR appeared higher in the control groups. These obvious infective signs, such as necrotic tissue, osteolysis, and diffusive infiltration of inflammatory cells from observations of the macroscopic test, X-ray, and histological examinations, respectively, occurred in the animals without vancomycin-loaded coating. However, the antibacterial performance of the vancomycin group was impressive. Not only did it prevent animal deaths but also it demonstrated excellent antibacterial performance, such as relatively normal biochemical markers, slight soft-tissue swelling, new bone formation, and fewer inflammatory cells. Poelstra et $\mathrm{al}^{35}$ reported that bacterial adhesion onto the implanted surfaces was critical for the pathogenesis of the implant-related infections, and an initial hours' postimplant "decisive period" was determined, during which prevention of bacterial adhesion was critical to infection prophylaxis. Therefore, we hypothesized that antibacterial effects of the vancomycin group toward $S$. aureus in vivo could have been attributed to the initial burst release of the vancomycin from the vancomycin-loaded coating.

This study has several limitations: 1) only one bacterial strain was investigated, 2) just one concentration of vancomycin was evaluated, and 3) longer-term efficacy of the vancomycin-loaded coating was not investigated in the present experiment. All of these limitations will be the subject of research in our future work.

\section{Conclusion}

Vancomycin-coated titanium implants prepared by an electrospinning nanotechnique exerted antibacterial properties in vitro and in vivo. This therefore may be a promising approach to preventing and treating implant-associated infections.

\section{Acknowledgment}

This work was supported by the National Natural Science Foundation of China (81171745).

\section{Disclosure}

The authors report no conflicts of interest in this work.

\section{References}

1. Vester H, Wildemann B, Schmidmaier G, Stöckle U, Lucke M. Gentamycin delivered from a PDLLA coating of metallic implants: in vivo and in vitro characterisation for local prophylaxis of implant-related osteomyelitis. Injury. 2010;41(10):1053-1059.

2. Harris LG, Richards RG. Staphylococci and implant surfaces: a review. Injury. 2006;37(2):S3-S14.

3. Del Pozo JL, Patel R. Infection associated with prosthetic joints. $N$ Engl J Med. 2009;361(8):787-794.

4. Hanssen AD, Spangehl MJ. Practical applications of antibiotic-loaded bone cement for treatment of infected joint replacements. Clin Orthop Relat Res. 2004;427:79-85.

5. Diefenbeck M, Mückley T, Hofmann GO. Prophylaxis and treatment of implant-related infections by local application of antibiotics. Injury. 2006;37(2):S95-S104

6. Gulati K, Aw MS, Findlay D, Losic D. Local drug delivery to the bone by drug-releasing implants: perspectives of nano-engineered titania nanotube arrays. Ther Deliv. 2012;3(7):857-873.

7. van de Belt H1, Neut D, Schenk W, van Horn JR, van der Mei HC, Busscher HJ. Infection of orthopedic implants and the use of antibioticloaded bone cements: a review. Acta Orthop Scand. 2001;72(6): 557-571.

8. Zimmerli W, Sendi P. Pathogenesis of implant-associated infection: the role of the host. Semin Immunopathol. 2011;33:295-306.

9. Edin ML, Miclau T, Lester GE, Lindsey RW, Dahners LE. Effect of cefazolin and vancomycin on osteoblasts in vitro. Clin Orthop Relat Res. 1996;333:245-251.

10. Rathbone CR, Cross JD, Brown KV, Murray CK, Wenke JC. Effect of various concentrations of antibiotics on osteogenic cell viability and activity. J Orthop Res. 2011;29(7):1070-1074.

11. Tran PA, Sarin L, Hurt RH, Webster TJ. Opportunities for nanotechnologyenabled bioactive bone implants. J Mater Chem. 2009;19(18): 2653-2659.

12. Ji W, Sun Y, Yang F, et al. Bioactive electrospun scaffolds delivering growth factors and genes for tissue engineering applications. Pharm Res. 2011;28(6):1259-1272.

13. Boland ED, Matthews JA, Pawlowski KJ, Simpson DG, Wnek GE Bowlin GL. Electrospinning collagen and elastin: preliminary vascular tissue engineering. Front Biosci. 2004;9:1422-1432.

14. Yoshimoto H, Shin Y, Terai H, Vacanti J. A biodegradable nanofiber scaffold by electrospinning and its potential for bone tissue engineering. Biomaterials. 2003;24(12):2077-2082.

15. Yang F, Murugan R, Wang S, Ramakrishna S. Electrospinning of nano/ micro scale poly (L-lactic acid) aligned fibers and their potential in neural tissue engineering. Biomaterials. 2005;26(15):2603-2610.

16. Sahoo S, Ouyang H, Goh JC-H, Tay T, Toh S. Characterization of a novel polymeric scaffold for potential application in tendon/ligament tissue engineering. Tissue engineering. 2006;12(1):91-99. 
17. Torres-Giner S, Martinez-Abad A, Gimeno-Alcañiz JV, Ocio MJ, Lagaron JM. Controlled delivery of gentamicin antibiotic from bioactive electrospun polylactide-based ultrathin fibers. Adv Eng Mater. 2012; 14(4):B112-B122.

18. Said SS, El-Halfawy OM, El-Gowelli HM, Aloufy AK, Boraei NA, El-Khordagui LK. Bioburden-responsive antimicrobial PLGA ultrafine fibers for wound healing. Eur J Pharm Biopharm. 2012;80(1):85-94.

19. Choi JS, Leong KW, Yoo HS. In vivo wound healing of diabetic ulcers using electrospun nanofibers immobilized with human epidermal growth factor (EGF). Biomaterials. 2008;29(5):587-596.

20. Trampuz A, Piper KE, Jacobson MJ, et al. Sonication of removed hip and knee prostheses for diagnosis of infection. $N$ Engl J Med. 2007; 357(7):654-663.

21. Arens S, Schlegel U, Printzen G, Ziegler W, Perren S, Hansis M. Influence of materials for fixation implants on local infection an experimental study of steel versus titanium DCP in rabbits. J Bone Joint Surg Br. 1996;78(4):647-651.

22. Darouiche RO. Treatment of infections associated with surgical implants. N Engl J Med. 2004;350(14):1422-1429.

23. Kurtz SM, Lau E, Schmier J, Ong KL, Zhao K, Parvizi J. Infection burden for hip and knee arthroplasty in the United States. J Arthroplasty. 2008;23(7):984-991.

24. Gollwitzer H, Ibrahim K, Meyer H, Mittelmeier W, Busch R, Stemberger A. Antibacterial poly (D, L-lactic acid) coating of medical implants using a biodegradable drug delivery technology. J Antimicrob Chemother. 2003;51(3):585-591.

25. Schmidmaier G, Lucke M, Wildemann B, Haas NP, Raschke M. Prophylaxis and treatment of implant-related infections by antibiotic-coated implants: a review. Injury. 2006;37(2):S105-S112.

26. Hardes J, Von Eiff C, Streitbuerger A, et al. Reduction of periprosthetic infection with silver-coated megaprostheses in patients with bone sarcoma. J Surg Oncol. 2010;101(5):389-395.
27. Fiedler J, Kolitsch A, Kleffner B, Henke D, Stenger S, Brenner RE. Copper and silver ion implantation of aluminium oxide-blasted titanium surfaces: proliferative response of osteoblasts and antibacterial effects. Int J Artif Organs. 2011;34(9):882-888.

28. Reneker DH, Chun I. Nanometre diameter fibres of polymer, produced by electrospinning. Nanotechnology. 1996;7(3):216.

29. Zhang Y, Su B, Venugopal J, Ramakrishna S, Lim C. Biomimetic and bioactive nanofibrous scaffolds from electrospun composite nanofibers. Int J Nanomedicine. 2007;2(4):623.

30. Bhardwaj N, Kundu SC. Electrospinning: a fascinating fiber fabrication technique. Biotechnol Adv. 2010;28(3):325-347.

31. Gilchrist SE, Lange D, Letchford K, Bach H, Fazli L, Burt HM. Fusidic acid and rifampicin co-loaded PLGA nanofibers for the prevention of orthopedic implant associated infections. J Control Release. 2013;170(1):64-73.

32. Puppi D, Piras AM, Detta N, Dinucci D, Chiellini F. Poly (lactic-coglycolic acid) electrospun fibrous meshes for the controlled release of retinoic acid. Acta Biomater. 2010;6(4):1258-1268.

33. Li L-1, Wang L-M, Xu Y, Lv L-X. Preparation of gentamicin-loaded electrospun coating on titanium implants and a study of their properties in vitro. Arch Orthop Trauma Surg. 2012;132(6):897-903.

34. Tseng Y-Y, Kao Y-C, Liao J-Y, Chen W-A, Liu S-J. Biodegradable drug-eluting poly [lactic-co-glycol acid] nanofibers for the sustainable delivery of vancomycin to brain tissue: in vitro and in vivo studies. ACS Chem Neurosci. 2013;4(9):1314-1321.

35. Poelstra KA, Barekzi NA, Rediske AM, Felts AG, Slunt JB, Grainger DW. Prophylactic treatment of gram-positive and gram-negative abdominal implant infections using locally delivered polyclonal antibodies. J Biomed Mater Res. 2002;60(1):206-215.
International Journal of Nanomedicine

\section{Publish your work in this journal}

The International Journal of Nanomedicine is an international, peerreviewed journal focusing on the application of nanotechnology in diagnostics, therapeutics, and drug delivery systems throughout the biomedical field. This journal is indexed on PubMed Central, MedLine, CAS, SciSearch ${ }^{\circledR}$, Current Contents ${ }^{\circledR} /$ Clinical Medicine,

\section{Dovepress}

Journal Citation Reports/Science Edition, EMBase, Scopus and the Elsevier Bibliographic databases. The manuscript management system is completely online and includes a very quick and fair peer-review system, which is all easy to use. Visit http://www.dovepress.com/ testimonials.php to read real quotes from published authors. 